\title{
Pemimpin: Sebuah Komposisi Karawitan
}

\author{
BAMBANG SRI ATMOJO* \\ Jurusan Karawitan, Fakultas Seni Pertunjukan, \\ Institut Seni Indonesia Yogyakarta
}

\begin{abstract}
The Leaders. This karawitan compotition based on the current situations of Indonesian political leaders and government. As we can see from printed and electronic media, there are political leaders and government people who corrupt, violate the laws, and so on. This has inspired the writer to write a piece of karawitan composition entitled "The Leader". In this composition, the writer is trying to criticize the situations, give some moral messages, and ask people not to follow the bad examples of those leaders. The process of composition has involved phases like exploration of the ideas, improvisation, and composition. This composition is played softly in laras pelog patet barang and it can take the form of ladrang, ayak-ayak, lancaran and playon.
\end{abstract}

Key words: Ladrang, ayak-ayak, lancaran, and playon.

\section{Pendahuluan}

Pemimpin yang dimaksud dalam tulisan ini adalah seseorang yang mempunyai jabatan sebagai pemimpin, baik pemimpin negara ditingkat pusat, daerah, majelis, dewan, instansi pemerintah maupun swasta dan sebagainya. Sebagai pimpinan sudah semestinya seseorang mempunyai sifat perwatakan yang baik, yaitu segala pikiran, anganangan, tutur kata, tindakan dan perilakunya dikendalikan oleh sifat baik yang sejati. Artinya baik yang tidak hanya untuk dirinya sendiri, tetapi juga baik untuk sesama manusia.

Melihat fenomena yang terjadi di negeri Indonesia tercinta baik lewat media cetak maupun media elektronik, mewartakan adanya beberapa pimpinan atau pejabat melakukan hal yang tidak baik bahkan sampai harus berurusan dengan aparat penegak hukum. Fenomena-fenomena itu menarik perhatian untuk dikritisi dan mendorong timbulnya gagasan atau ide membuat karya komposisi karawitan. Sifat dan perilaku pemimpin yang tidak baik tersebut, menjadi sumber inspirasi penciptaan terutama dalam membuat cakepan atau lirik lagu dengan tema ajakan atau kritikan kepada pemimpin agar menghindari sifat dan perilaku tidak baik. Maka komposisi ini diberi judul "Pemimpin".

Ada yang ingin dicapai dalam penciptaan ini, yaitu bagaimana membuat komposisi karawitan yang dapat menyampaikan pesan moral terhadap penonton atau pendengar pada umumnya dan para pemimpin pada khususnya.

Sesuai dengan rumusan ide di atas, tujuan yang ingin dicapai dalam penciptaan ini adalah mencoba mengekspresikan pesan moral terhadap penonton atau pendengar pada umumnya dan para pemimpin pada khususnya dalam bentuk komposisi karawitan.

\section{Metode Penciptaan}

Sesuai dengan permasalahan yang diajukan ada beberapa langkah yang perlu dilakukan dalam penciptaan ini, yaitu:

\section{Tahap Persiapan}

Dalam tahap persiapan suatu langkah yang dilakukan pertama kali yaitu studi pustaka agar mendapatkan bahan referensi, sehingga dapat menuntun perwujudan komposisinya.

*Alamat Korespondensi: Jln. Parangtritis KM. 6,5 Sewon, Yogyakarta. Tlp. 0274-375380 HP: 08121574102 


\section{Tahap Pelaksanaan}

Dari data tersebut dipelajari, dianalisis, kemudian mengadakan penciptaan dari hasil yang didapatkan. Untuk menuangkan berbagai macam ide ke dalam suatu penyajian ditempuh melalui :

Eksplorasi

Di dalam langkah ini dilakukan pendekatan, penjelajahan, penjajakan terhadap objek secara intensif untuk mendapatkan data tentang sifat dan perilaku pemimpin yang tidak baik sebagai bahan dasar penciptaan lirik lagu. Dari langkah tersebut didapat ide mengenai tema karya dan sekaligus sebagai judul karya yaitu "Pemimpin". Selanjutnya mencari pola garapan lagu baik garap instrumen maupun vokal, laras, patet, bentuk gending, pola penyajian, cengkok dan kembangan/ sekaran. Perpaduan alur lagu dan lirik lagu perlu diperhitungkan agar hasil garapannya tidak terdapat kejanggalan demi kesatuan garap.

\section{Improvisasi}

Improvisasi mempunyai pengertian penciptaan sesuatu tanpa persiapan lebih dahulu dan atau pembuatan sesuatu berdasarkan bahan yang ada atau seadanya. Menurut Jacqueline Smith (1985:31), improvisasi itu spontan, kreasi sementara, tidak tetap/baku, tidak berbentuk selesai. Berpijak dari pengertian di atas, improvisasi dalam penciptaan ini yaitu membuat motif lagu, kalimat lagu, lirik lagu dan sebagainya baik secara spontan maupun dengan bekal yang didapat sewaktu bereksplorasi. Penuangan ide ke dalam motif lagu ataupun kalimat lagu direalisasikan baik dengan cara bersenandung atau rengengrengeng maupun menggunakan instrumen gamelan. Garapan motif lagu, kalimat lagu, lirik lagu, bentuk, irama, pola penyajian dan dinamika yang telah ditentukan dicoba dimainkan dengan dibantu orang lain untuk pemantapan garap, juga untuk mendapatkan berbagai pengembangan dan variasinya.

\section{Komposisi}

Komposisi mempunyai beberapa pengertian antara lain: susunan atau tata susun, dalam dunia musik berarti gubahan baik instrumen maupun vokal, teknik menyusun karangan hingga menjadi ceritera yang indah dan selaras. Dengan merujuk pengertian tersebut, komposisi dalam penciptaan ini adalah teknik menyusun lagu baik instrumen maupun vokal hingga menjadi suatu bentuk karya yang indah dan selaras.

Tahap ini merupakan tahap penyusunan motif-motif lagu, kalimat lagu, bentuk lagu, garap vokal, garap instrumen, irama penyajian dan pola penyajian hingga menjadi sebuah komposisi karawitan yang utuh. Untuk mewujudkan sebuah komposisi yang dapat dinikmati secara utuh dan menimbulkan sentuhan emosional, maka disusunlah lagu baik instrumental maupun vokal secara konstruksional.

\section{Bentuk Penyajian Komposisi Pemimpin}

Penciptaan komposisi Pemimpin akan berjalan lancar dan terwujud dengan baik apabila dalam penyusunannya memiliki konsep garapan yang matang. Konsep merupakan modal dasar mengaplikasikan ide garapan, sehingga garapan yang ingin dikomunikasikan sampai pada penonton. Konsep garapan komposisi Pemimpin adalah untuk sajian berdiri sendiri (konser karawitan) yang khusus dinikmati keindahan musikalnya dan pesan moralnya. Namun demikian faktor keindahan yang lain seperti tata panggung, tata lampu, tata busana, penataan instrumen dan sikap pemain tetap mendapat perhatian demi tercapainya keutuhan garap penyajian.

Komposisi merupakan istilah baru di dalam dunia seni karawitan, yang diperkirakan muncul dan digunakan pada era 70-an di kalangan pendidikan formal kesenian. Istilah lama yang digunakan dan bermakna kurang lebih sama atau mirip dengan komposisi adalah lagu atau gending (Supanggah,1996:1). Pengertian gending dalam arti luas adalah semua komposisi lagu gamelan. Gending itu memiliki perincian struktur, misalnya berbentuk mawur, jangga/semang, candra/sarayuda, ladrang, ketawang, bubaran, lancaran, ayak-ayak, srepeg dan playon. Gending dalam arti khusus adalah penggolongan komposisi lagu gamelan yang satu gongan terdiri atas 64 tabuhan balungan seperti bentuk candra atau sarayuda kethuk 2 kerep dhawah kethuk 4, atau kelipatannya seperti bentuk semang atau jangga kethuk 4 kerep dhawah kethuk 8, bentuk mawur kethuk 8 kerep dhawah 16 dan bentuk pengrawit kethuk 8 arang dhawah kethuk 16 .

Seni karawitan Jawa khususnya gaya Yogyakarta pada dasarnya mempunyai dua bentuk penyajian yaitu garap soran dan lirihan. Soran adalah bentuk 
penyajian karawitan yang dibawakan dengan ditabuh keras terutama oleh kelompok instrumen balungan yaitu saron demung, saron ricik, peking dan kelompok instrumen bonang yaitu bonang penembung, bonang barung dan bonang penerus. Pengertian keras di dalam tabuhan gamelan adalah keras dalam arti uyon-uyon, maksudnya walaupun gamelan ditabuh keras akan tetapi faktor keseimbangan dan rasa indah lagu tetap dipegang dan terpenuhi. Adapun lirihan adalah bentuk penyajian karawitan yang dibawakan dengan ditabuh lirih, maka ungkapan rasa yang dicurahkan dalam tabuhan lirihan bersifat lembut atau halus. Di dalam penyajian garap lirihan mengedepankan instrumen yang sifatnya halus, lembut antara lain rebab, gender barung, gender penerus, gambang, siter dan suling. Penyajian garap lirihan biasanya dibawakan bersama-sama dengan vokal jenis sindhenan, gerongan, bawa, celuk, sekar, senggakan dan alok. Pada garapan gending tertentu sering pula disertai tepuk tangan yang meramaikan dan menyemarakkan keindahan lagu.

Setelah mengetahui bentuk penyajian karawitan baik garap soran maupun lirihan, selanjutnya akan dipaparkan bentuk penyajian komposisi Pemimpin. Komposisi Pemimpin merupakan lagu garap lirihan, untuk membahas konsep garap penyajiannya dapat dilihat melalui beberapa elemen.

\section{Tata Panggung}

Panggung yang dimaksud dalam hal ini adalah tempat untuk menggelar sebuah pertunjukan. Panggung untuk penyajian seni karawitan biasanya bertempat di pendhapa atau ndalem, selain itu dapat juga disajikan di stage, studio dan dapat juga di panggung yang dibuat dari papan sesuai dengan kebutuhannya. Penyajian komposisi Pemimpin pada prinsipnya dapat disajikan pada salah satu panggung tersebut di atas, dan pernah disajikan empat kali pada tempat yang berbeda yaitu pertama di studio RRI Nusantara II Yogyakarta dalam acara siaran langsung uyon-uyon seton (uyon-uyon yang diselenggarakan setiap hari sabtu) pada tanggal 26 April 2008. Kedua di pendhapa Parasamya Kabupaten Bantul dalam acara "konser karawitan" oleh Himpunan Mahasiswa Jurusan (HMJ) Seni Karawitan Fakultas Seni Pertunjukan Institut Seni Indonesia Yogyakarta pada tanggal
25 Mei 2008. Ketiga di alun-alun Wates, Kulon Progo dalam acara peringatan hari jadi Kabupaten Kulon Progo ke 57 pada tanggal 15 Oktober 2008 dengan panggung yang dibuat dari papan. Keempat di halaman Rektorat ISI Yogyakarta dalam acara wisuda sarjana dan pascasarjana pada tanggal 25 Oktober 2008 juga dengan panggung dari papan.

\section{Instrumen}

Media ungkap yang digunakan untuk mewujudkan karya ini yaitu seperangkat gamelan ageng laras pelog. Penggunaan gamelan dalam penyajian komposisi "Pemimpin" lebih mengutamakan kualitas larasan daripada wujud atau bentuk gamelan, karena kualitas gamelan ini sangat menentukan keberhasilan penyajiannya. Adapun instrumen gamelan ageng yang dipilih untuk garapan ini yaitu: (1) kendang ageng, batangan dan ketipung; (2) gender barung; (3) gender penerus; (4) gambang; (5) rebab; (6) suling; (7) siter atau clempung; (8) slentem; (9) demung; (10) saron; (11) peking; (12) bonang barung; (13) bonang penerus; (14) ketuk kenong; dan (15) kempul gong.

\section{Penataan Instrumen}

Penataan instrumen gamelan Jawa, baik gamelan wayangan, gamelan ageng, gamelan uyonuyon, gamelan gadhon, gamelan siteran maupun gamelan pakurmatan, oleh para empu karawitan telah dipikirkan dengan seksama baik dari segi keseimbangan, kepraktisan, keindahan, fungsi, bahkan sampai pada peranan instrumennya. Setiap perangkat gamelan tersebut, mempunyai penataan instrumen yang berbeda-beda. Untuk satu perangkat gamelan saja, misalnya perangkat gamelan uyon-uyon dapat juga terjadi bermacammacam model penataan instrumen, hal ini antara lain disesuaikan dengan tempat, fungsi dan garapan gending. Penataan yang disesuaikan dengan tempat misalnya di pendhapa, ndalem, stage, studio atau panggung terbuka. Penataan instrumen yang disesuaikan dengan fungsi misalnya untuk sajian uyon-uyon, iringan tari atau iringan wayang. Penataan yang disesuaikan dengan bentuk garapan misalnya garap tradisi atau garap non tradisi. Penataan instrumen pada penyajian karya ini juga mempertimbangkan beberapa hal tersebut di atas. 


\section{Bentuk Gending}

Di dalam olah seni karawitan, lagu merupakan salah satu unsur pokok. Lagu adalah susunan nada-nada yang diatur dalam gatra, berirama dan memiliki rasa musikal. Susunan nada-nada itu mengarah pada suatu bentuk, sehingga lahir bermacam-macam bentuk gending antara lain ladrang, ketawang, ayak-ayak, srepeg, playon, sampak, mawur, jangga, candra, lahela dan sebagainya. Hasil penciptaan komposisi Pemimpin, walaupun memiliki rasa musikal baru, lirik lagu baru, pola garap penyajiannya baru, tetapi bentuk gendingnya masih menggunakan bentuk tradisi. Dengan demikian komposisi Pemimpin laras pelog patep barang merupakan karya lagu baru dengan bentuk ladrang, ayakayak, lancaran dan playon dalam garap lirihan.

\section{Irama}

Pada bagian bentuk gending telah disebutkan bahwa lagu merupakan salah satu unsur pokok dalam olah seni karawitan, adapun unsur yang lain yaitu irama. Kaitannya dengan gending, irama adalah pelebaran dan penyempitan gatra. Artinya tingkatan pengisian di dalam gatra, mulai dari tiap gatra berisi 4 titik yang berarti satu slag balungan berisi satu titik, meningkat menjadi kelipat-kalipatannya hingga satu slag balungan dapat diisi dengan 16 titik, demikian sebaliknya (Martopangrawit, 1975:3). Dengan demikian irama mengandung unsur waktu dan isian yang kesatuan dari keduanya menghasilkan 5 tingkatan irama yaitu lancar (irama 1/2), tanggung (irama I), dados (irama II), wiled (irama III), dan wiled rangkep (irama IV).

Dalam garap penyajian komposisi Pemimpin menggunakan dua jenis irama yaitu irama terikat (metris) dan irama bebas (ritmis). Irama metris yang dimaksud adalah irama lancar, tanggung, dados, wiled, dan wiled rangkep. Irama ritmis sulit ditentukan jumlah ketukannya, panjang pendeknya, temponya yang tidak selalu konstan seperti gending bersifat metris yang ajeg ketukannya. Penggunaan irama bebas atau merdika yaitu diterapkan pada penyajian sekar Pucung.

\section{Garap Vokal}

Garap merupakan tindakan kreatif seorang pengrawit dalam mengembangkan dan membuat tafsir suatu lagu baik berupa sajian vokal maupun instrumental. Maka garap dalam berolah seni karawitan merupakan faktor penting dalam mencapai kualitas hasil sajian. Eksistensi garap ini bila sudah mempola akan melahirkan cengkok. Dalam penciptaan ini, penulis membuat garapan vokal yang cengkok dan lirik lagunya khusus untuk komposisi Pemimpin. Hasil penciptaan vokal yang dilakukan yaitu dalam bentuk gerongan, rumpakan dan sekar.

\section{Garap Penyajian}

Garap penyajian komposisi Pemimpin tidak jauh berbeda dengan penyajian gending-gending tradisi. Untuk memudahkan uraian garap penyajiannya yang terdiri dari 6 bagian lagu, maka dipaparkan perbagian seperti berikut.

Lagu bagian pertama: ladrang pelog pathet barang

\section{Buka Bonang:}

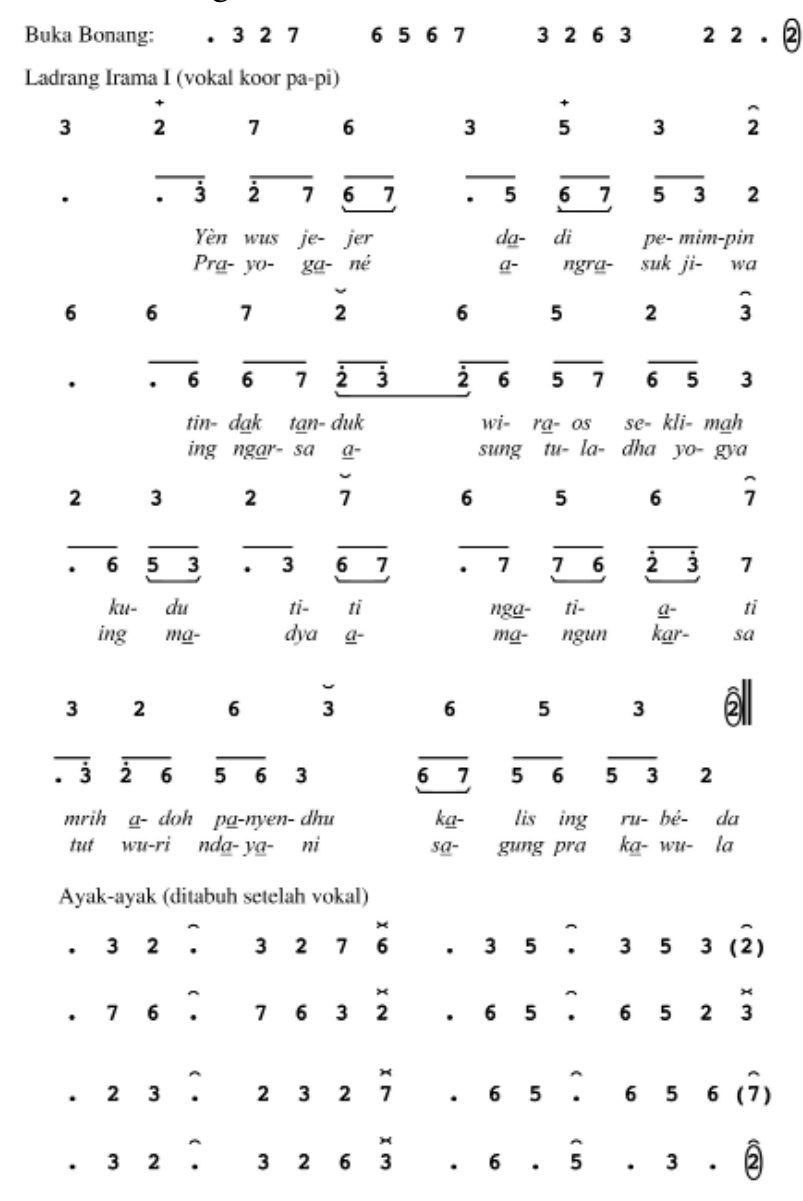

Lagu bagian pertama berbentuk ladrang disajikan dalam irama I (tanggung), diawali dari instrumen bonang barung dengan pola garap penyajian: (1) kendangan ladrang kendang 
kalih disajikan satu ulihan; (2) kendangan kebar disajikan tiga ulihan; (3) kendang kalih dengan garap sirep, isi vokal rumpakan koor putra-putri disajikan satu ulihan; (4) kendangan kebar, dalam bentukgending ayak-ayak disajikan satu ulihan; (5) kendang kalih dengan garap sirep, isi vokal rumpakan koor putra-putri disajikan satu ulihan terus masuk irama II (dados).

Lagu bagian kedua

Irama II (suara I pi- suara II pa)

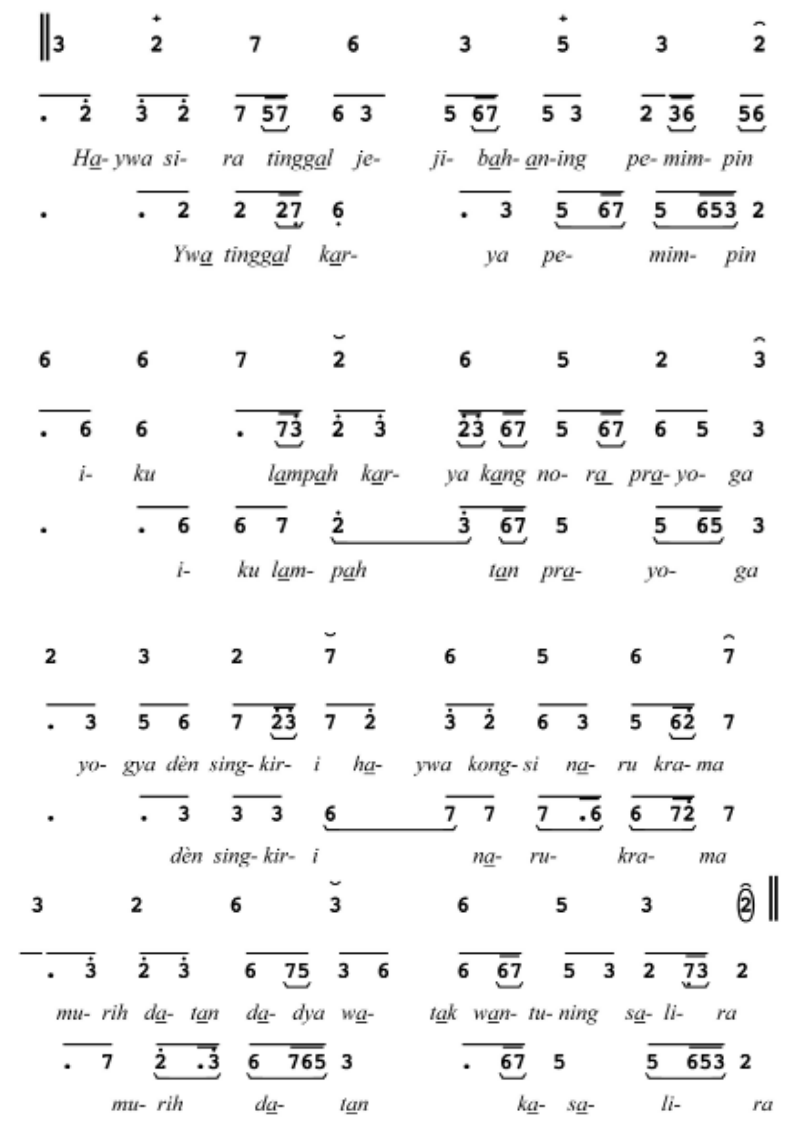

Lagu bagian kedua berbentuk ladrang disajikan dalam irama II, dengan garap vokal suara I koor putri dan suara II koor putra, disajikan satu ulihan terus masuk irama III (wiled).

Lagu bagian ketiga

Irama III

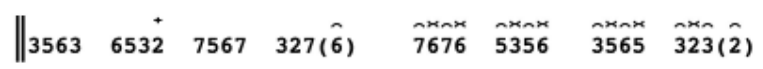

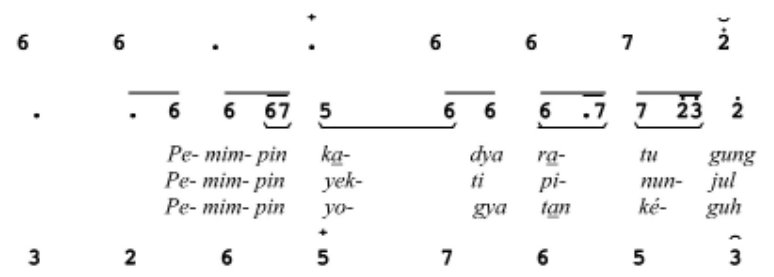



Sekar Pucung: (oleh putri dengan irama ritmis) Lagu bagian ketiga berbentuk ladrang

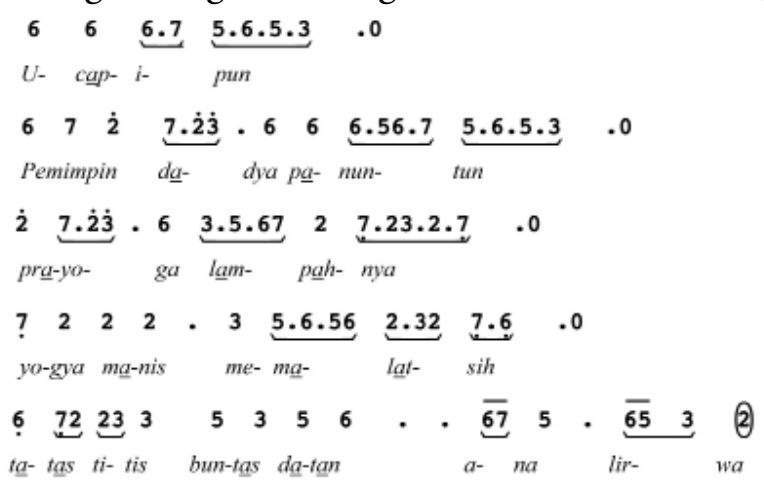

kendangan ciblon, disajikan dua ulihan. Ulihan pertama disajikan dalam irama III dan menjelang gong masuk irama IV (wiled rangkep). Ulihan kedua pada baris kenong pertama disajikan dalam irama IV, pada baris kenong kedua kembali irama III dan pada kempul ketiga berhenti andhegan/ kendelan, kemudian sekar Pucung dilagukan tunggal putri dilanjutkan lancaran.

Lagu bagian keempat

Lancaran Pelog Patet Barang (vokal koor putraputri)

Lagu bagian keempat berbentuk lancaran, 


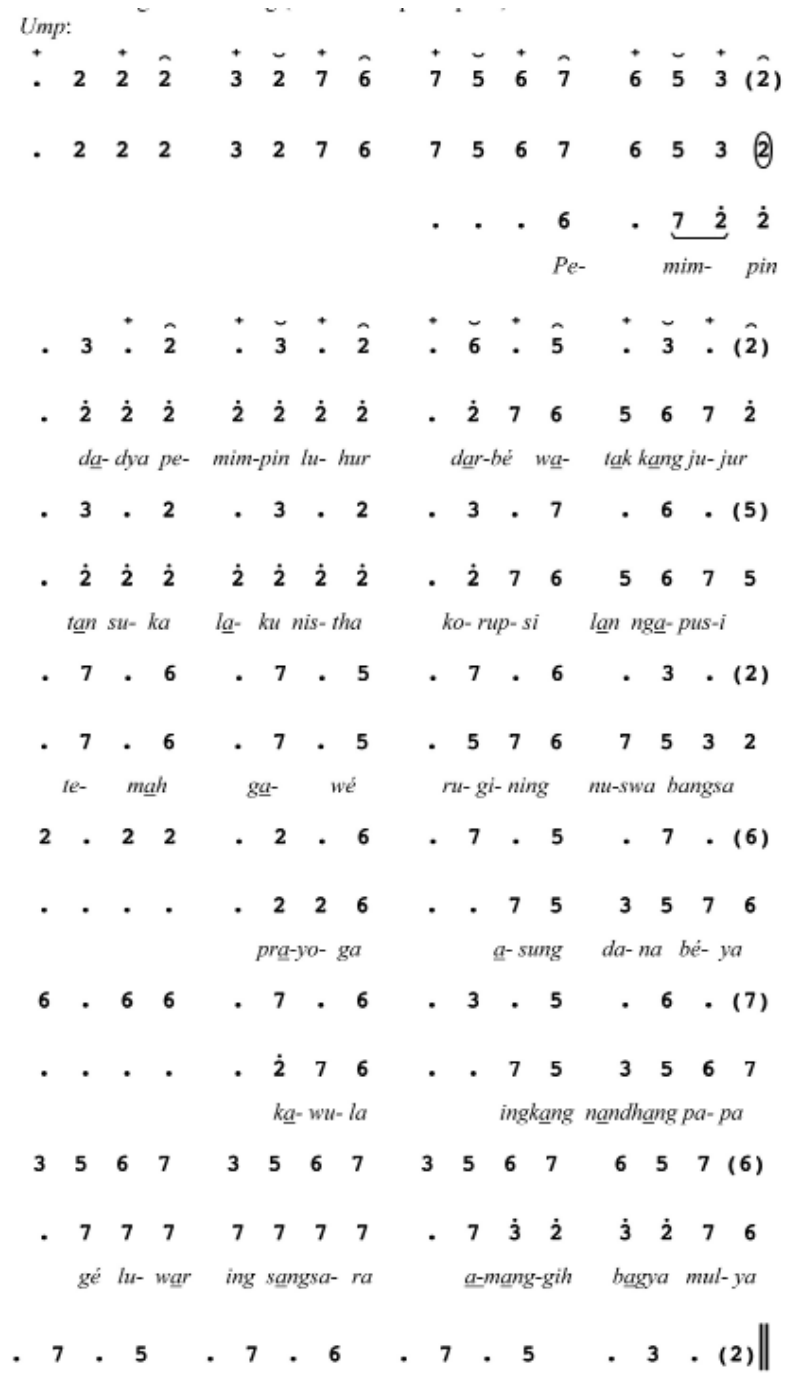

garap vokal koor putra-putri, disajikan dua atau tiga ulihan suwuk, kemudian masuk ladrang irama II dengan laya antal (pelan).

Lagu bagian kelima

Ladrang irama II (balungan ngracik)

Lagu bagian kelima berbentuk ladrang



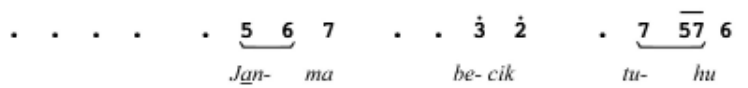$$
\begin{array}{lllllllllllllllll}
3 & 5 & 6 & 7 & 6 & 5 & 3 & 2 & 3 & 5 & . & 5 & & 7 & 6 & 5 & 3
\end{array}
$$

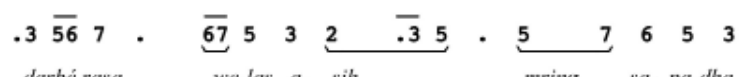$$
\text { darbérasa we-lạs a- sih mring sa-pa-dha }
$$

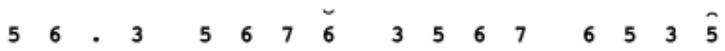

$$
\text { su- ka te- tu- lumg mring fa-kir miskin }
$$$$
\begin{array}{llllllllllllllll}
2 & 3 & 5 & - & 2 & 3 & 5 & 6 & 7 & 7 & 6 & 4 & 2 & 3 & 4 & 2
\end{array}
$$

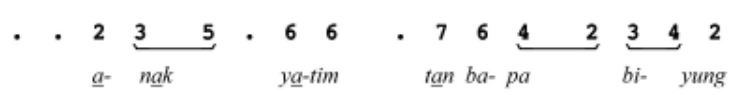

disajikan dalam irama II dengan laya antal. Lagu ini hanya digarap dengan instrumen gender barung, slentem, ketuk-kenong dan kempul gong, garap vokal koor putri, disajikan satu ulihan dilanjutkan playon.

Lagu bagian keenam

Playon
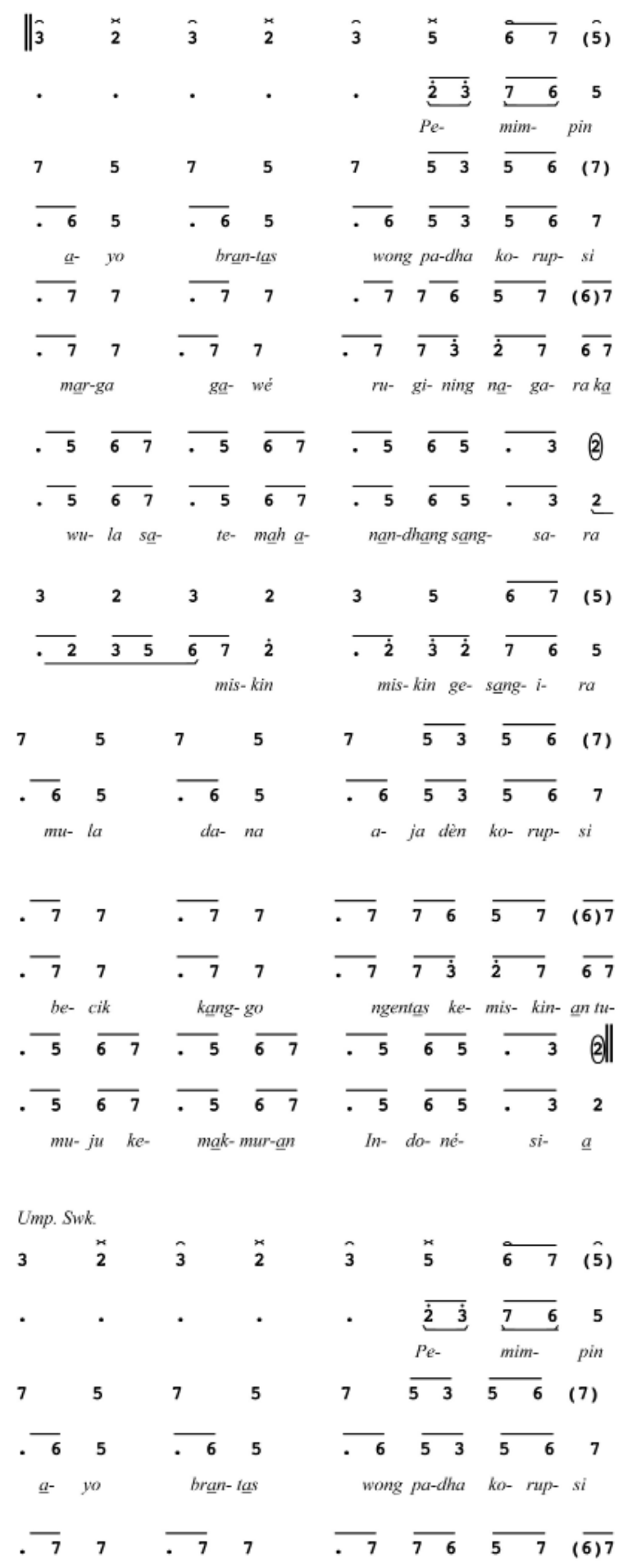

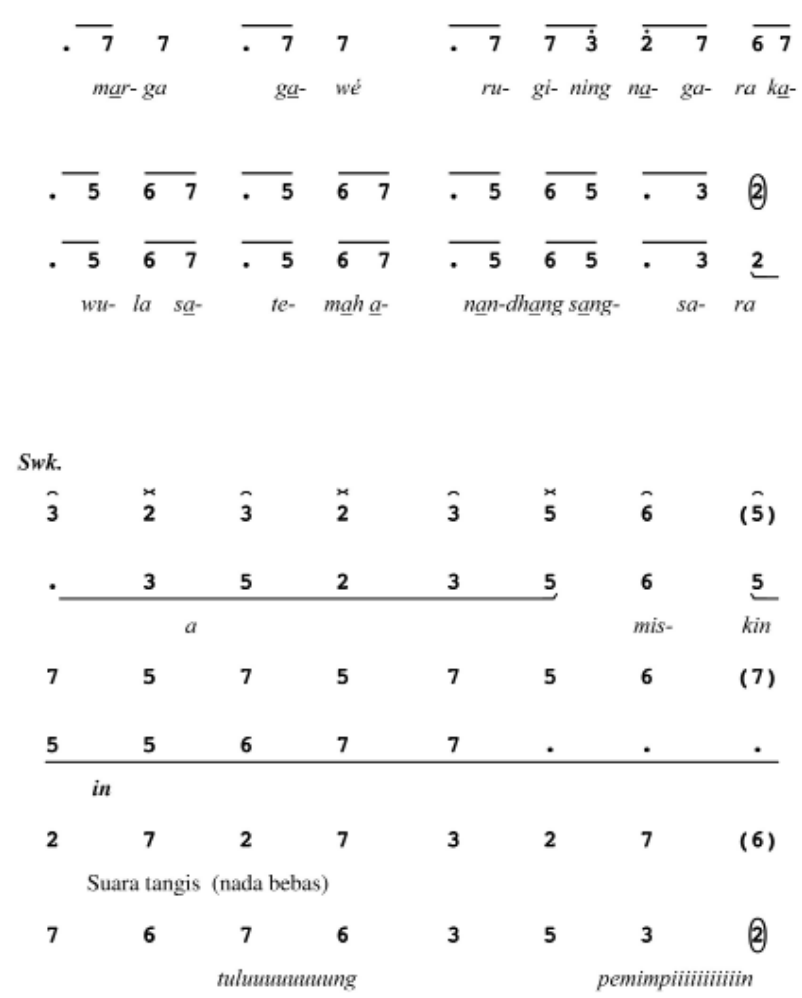

Lagu bagian keenam berbentukplayon disajikan tiga ulihan. Ulihan pertama disajikan dalam laya antal, dengan garap instrumental, kemudian sirep isi vokal koor putra-putri. Ulihan kedua disajikan dalam laya sedang, dengan garap instrumental, kemudian sirep isi vokal koor putra-putri. Ulihan ketiga disajikan dalam laya seseg (cepat), dengan garap instrumental, kemudian sirep isi vokal pada bagian umpak suwuk terus masuk bagian suwuk. Suara tangisan oleh putra dan putri dengan nada bebas, kemudian teriakan tulung oleh putri dan teriakan pemimpin oleh putra sebagai tanda akhir penyajian komposisi Pemimpin.

\section{Penutup}

Penciptaan komposisi karawitan yang berpijak pada seni tradisi, ternyata bukan pekerjaan mudah seperti yang kita bayangkan, tetapi didasari tekat dan kemauan yang sungguh-sungguh akhirnya penciptaan komposisi "Pemimpin" dapat terwujud. Karya seni merupakan cerminan perasaan, pengalaman dan pemikiran senimannya tentang kehidupan yang diungkapkan lewat bentuk-bentuk tertentu sesuai dengan "bahasa" masing-masing. Seni mengungkapkan pengalaman pribadi yang bersifat unik dalam interaksi manusia dengan realitas kehidupan. Bagi dunia seni sarana yang dipergunakan untuk menggumulinya tidak terbatas pada bahasa, tetapi seni mempergunakan sarana lain seperti bunyi, bentuk dan gerakan sebagai ekspresi estetis dalam membeberkan pengalaman pribadi seniman dengan berbagai aspek kehidupannya.

Komposisi Pemimpin merupakan ungkapan suara batin yang mempunyai harapan kepada pemimpin di negeri tercinta Indonesia agar menghindari sifat dan perilaku tidak baik. Komposisi Pemimpin laras pelog patet barang merupakan karya lagu baru dalam bentuk ladrang, ayak-ayak, lancaran dan playon dengan garap lirihan.

\section{Kepustakaan}

Fsy., "Perlu Dimunculkan Pemimpin Alternatif" Kedaulatan Rakyat, 15 Desember 2007, Yogyakarta.

Hastanto, Sri. "Karawitan Serba-Serbi Karya Ciptanya" dalam SENI, Jurnal Pengetahuan dan Penciptaan Seni. No. I/01 Mei 1991.

Martopangrawit, RL. 1975. Pengetahuan Karawitan 2. Surakarta: Akademi Seni Karawitan Indonesia Surakarta.

Poerwadarminto, W.J.S. 1939. Baoesastra Djawa. Batavia: N.V. Groningen

R-3, "Warga Tuntut Dukuh Kowen Mundur". Kedaulatan Rakyat. 18 Desember 2007, Yogyakarta

Sim., "37 Kejari Mandul Berantas Korupsi”, Kedaulatan Rakyat, 15 Desember 2007, Yogyakarta.

, "Tak Sadar Korupsi Dorong Kehancuran". Kedaulatan Rakyat. 10 Desember 2007, Yogyakarta.

Smith, Jacqualine. 1985. Komposisi Tari Sebuah Petunjuk Praktis Bagi Guru ( Terjemahan Ben Suharto). Yogyakarta: Ikalasti.

Soeroso. 1983. Menuju Ke Garapan Komposisi Karawitan. Yogyakarta: Akademi Musik Indonesia.

Supanggah, Rahayu. "Komposisi (baru) Karawitan" [Makalah Seminar] pada Jurusan Seni Karawitan Fakultas Seni Pertunjukan Institut Seni Indonesia Yogyakarta tanggal 21 Maret 1996.

Tim Penyusun. 1988. Kamus Bahasa Indonesia. Jakarta: Balai Pustaka

The Liang Gie. 2004. Filsafat Keindahan. Yogyakarta: Pusat Belajar Ilmu Berguna 